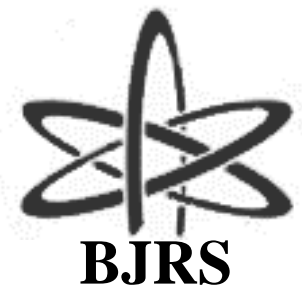

BRAZILIAN JOURNAL

$\mathrm{OF}$

RADIATION SCIENCES

08-03A (2020) 01-22

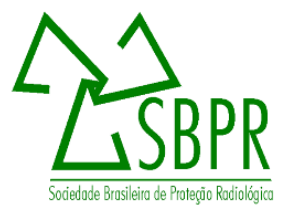

\title{
Impact of variable porosity models on the safety of high temperature pebble bed gas-cooled reactors
}

\author{
Abel Gámez Rodríguez, Leorlen Y Rojas Mazaira, Daniel Milian Perez, Dany \\ Sanchez Dominguez, Carlos Rafael García Hernández, Carlos Alberto Brayner De \\ Oliveira Lira \\ Nuclear Energy Department - UFPE \\ $C R C N-N E / C N E N$ \\ abel.rodriguez@ufpe.br
}

\begin{abstract}
The Very High Temperature Reactor (VHTR) is one of the candidates of next generation of the nuclear reactors according to IAEA. Predicting the thermohydraulic behavior of High Temperature Reactors (HTR) is an important contribution to the development of this technology. Evaluation of thermohydraulic performance and a comparison with experimental data were proposed to the international research community. The impact of porosity of pebble beds in the thermohydraulic performance in normal operation and under accident condition is the goal of many kinds of research. In this sense, the three-dimensional CFD thermohydraulic simulation of a HTR using ANSYS CFX has been done. The full-scale approach is used to study the influence of different porosity scheme in the main structural materials of the HTR-10 reactor. The porous medium model was used to simulate the pebble bed core zone and the discharge system of pebbles. A comparison with experimental data was made. The steady-state thermohydraulic performance of the HTR-10 reactor at normal operation and anticipated transients without scram (ATWS) tests result, were used. In this work, was possible to estimate the effect of the porosity in the interior regions of the reactor and the impact on the temperature distribution. Finally, the study broadens the knowledge about the impact that the use of variable porosity has on safety analyses in pebble beds reactors.
\end{abstract}

Keywords: Porosity models, HTR-10, CFD. 


\section{INTRODUCTION}

In recent years, the International Energy Agency (IEA) focuses attention on the dependence of fossil fuels in most countries in the world. It was concluded in [1] that more than $80 \%$ of global energy production uses fossil fuels. Also was a point on the huge $\mathrm{CO}_{2}$ emissions to the atmosphere, a factor that causes an increase in the greenhouse effect. Whereby, current energy matrix needs changes, where sources of clean (of non-fossil origin) to come in a stable and secure supply of energy for all.

On the other hand, the use of only non-fossil fuel and renewable energy sources for global energy production is currently not possible due to the technological difficulties that these types of sources have. The most favorable alternative is the diversification of currently used energy sources and the increased of known technologies more efficiently and safely ways.

Every day, the nuclear power industry improves and grows to exceed the levels of safety and reliability achieved until today. In this sense, the scientific community joined in the research and development of nuclear reactors that possess high resistance to proliferation, safer, with less waste and more economics.

The Very High Temperature Reactor (VHTR) is one of the candidates of the next generation of the nuclear reactor according to U.S. DOE Nuclear Energy Research Advisory Committee (NERAC) and the Generation IV International Forum (GIF) [2]. Evaluation of thermohydraulic performance and experimental comparison were proposed to the international research community. The HTR-10 was selected as a reference reactor of high temperature pebble bed gas-cooled reactor by IAEA [3] to study the performance of some technology components under different conditions.

The HTR-10 test reactor project has been carried out under the National High Technology Research and Development Program of China [4]. The 10 MW high temperature gas-cooled-test module (HTR-10) project was approved by the Chinese State Council in March 1992. The ground movement was started in 1994, and construction was completed in 2000. Its initial criticality was achieved on 1 December 2000. The design of the HTR-10 reactor represents the layout features of the modular HTGR. It was primarily characterized by inherent safety features. The HTR-10 test reactor should serve as a test facility to demonstrate the inherent safety features of the modular reactor design. It also helps to win the credit from regulatory bodies, utilities and the public [5]. 
Starting from the disclosure of the technology's features of the HTR-10, properties of the structural materials and used fuel, as well as the data of the different operating conditions tested [3], $[6,7]$, it was possible to adjust and validate computational models. These models allow the reliable, safe and inexpensive study of the behavior of the HTR-10 reactor under many operating and accident conditions. These models are part of the knowledge base for the creation of future reactors of very high temperatures. One of the most outstanding technologies is the use of fuel elements in the form of spherical elements to make up the core of the gas-cooled reactor.

The use of spherical fuel elements in a nuclear reactor has been studied throughout the last decades. Even today different experimental facilities are building to verify the effectiveness of this type of fuel element for future nuclear reactors. The study of the impact of the shape and structure of pebble beds in nuclear reactors core is of great relevance, fundamentally in the safety of future nuclear reactors.

In this sense, the impact of different models of porosity of the pebble bed that form the core of the high temperature reactor HTR-10 will be studied using computational fluid dynamics. The results will be compared with experimental data published in [3].

\section{MATERIALS AND METHODS}

\subsection{HTR-10 general Information}

The HTR-10 is a modular reactor where the reactor core is formed by graphite blocks. These blocks form a cylindrical core reactor which is cooled by helium gas. The nuclear fuel is encapsulated in spherical fuel elements which are piled into a pebble bed core. In normal operation, the reactor core is designed for a thermal power of $10 \mathrm{MW}$. The pressure of cooling gas and a mass flow rate in the primary circuit are $3.0 \mathrm{MPa}$ and $4.32 \mathrm{~kg} / \mathrm{s}$ respectively. The coolant cycle is closed between the reactor core and a steam generator with a gas temperature of $250^{\circ} \mathrm{C}$ at the inlet and $700^{\circ} \mathrm{C}$ at the reactor exit tube [5]. The schematic for the HTR-10 primary system is shown in Figure $1 \mathrm{a}$ ).

The HTR-10 core is composed of about 27000 spherical fuel elements (equilibrium core). Each fuel pebble contains an inner fuel zone of $50 \mathrm{~mm}$ diameter, with the coated TRISO (tri-structural isotropic) particles, and a fuel-free graphite shell of $5 \mathrm{~mm}$ thickness. 
Figure 1: HTR-10 reactor core. a) Schematic representation of HTR-10 with helium cooling flux. b) Geometric models of the solid structures.
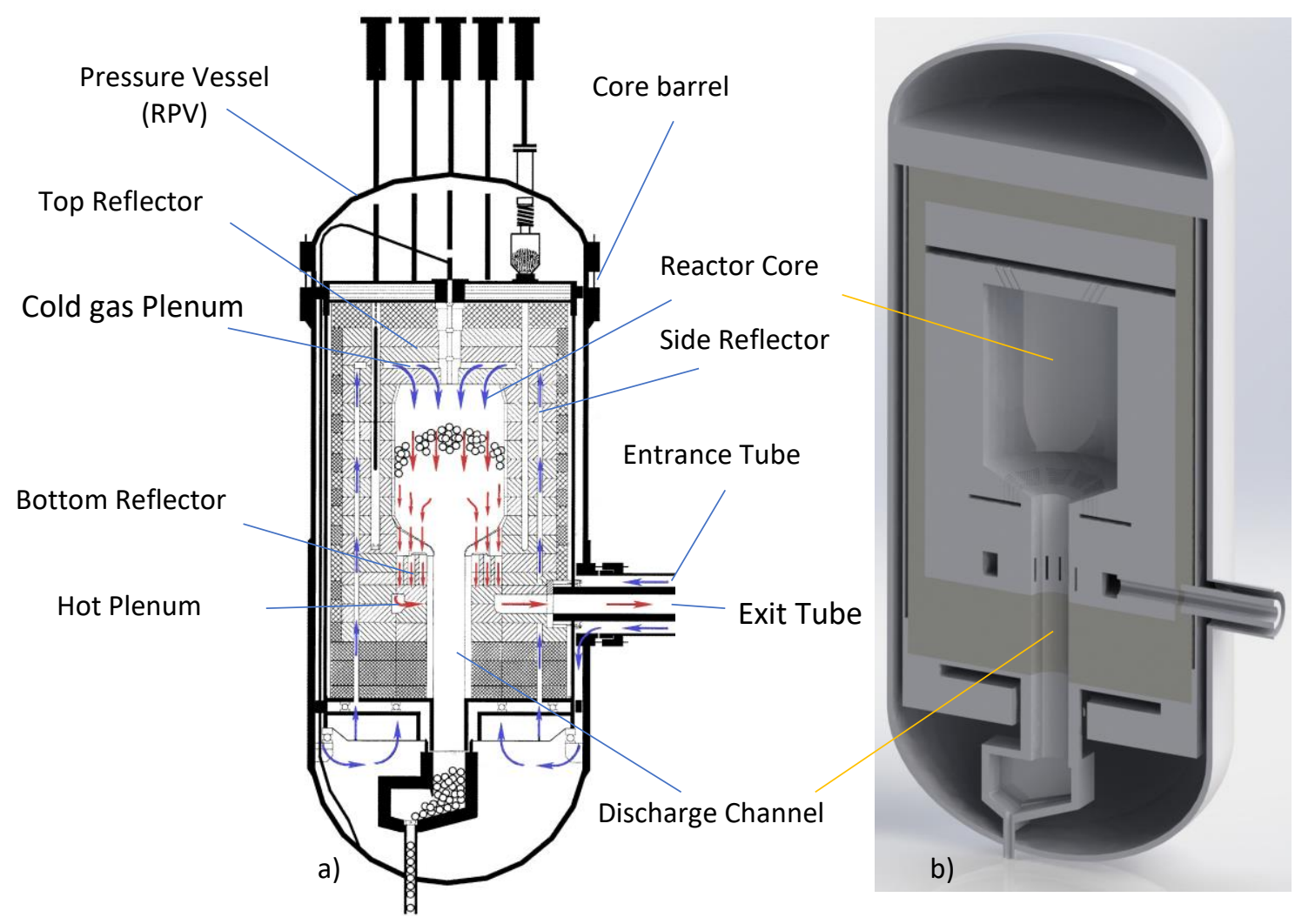

The bottom region of the core reactor is designed for a conical form to facilitate the free movement of the fuel elements by gravity. The whole active core zone is enclosed by graphite neutron reflectors. On the other hand, different parts denoted like the top, side, and bottom reflectors, enclosure the principal thermic zone as it was showed in Figure 1, b).

\subsection{General modeling of HTR-10}

For thermohydraulic simulation was implemented the methodology described by [1]. Firstly, it was necessary to represent the geometric regions that will be required for a correct understanding of the object of study. Foremost, it was necessary to unveil the geometric characteristics of the HTR10 reactor, described in the articles and the benchmark tasks. According to [2-8], the geometries of the basic bodies integrating the HTR-10 reactor were represented. For this, was used the design tools, Dassault System SolidWorks and ANSYS SpaceClaim. It was essential to represent the struc- 
tural parts that cover the study region (pebble bed reactor core) because that is where the experimental data measurement points are located.

The main structures were represented with simple curvatures and faces, which represent the distinctive characteristics of the parts, without losing the particular characteristics of each real structure. However, they were simplified to use the least amount of computational resources in the subsequent creation of the meshes (Figure 1,b)).

On the other hand, it is known that in both, during normal operation and through transients condition, there is a passive heat exchange system that acts between the reactor pressure vessel (RPV) and the cavities that surround the reactor. This system is described by several authors $[3,8-10]$. The detailed representation of this system was not carried out. Instead, it was approximated from mathematical equations the heat transfer of this system based on.

After obtaining all the geometric models in the real scale of the main solid parts of the reactor, it was necessary to represent the volumes that fill the spaces within these geometries, resulting in the representation of the helium cooling fluid.

In the other hand, a huge computational resource necessary to simulate the full realistic pebble beds HTR-10 reactor core $[13,14]$ instead of the this was proposed the porous media approach as is shown in Figure 2, b). Indeed, in this article, the pebble bed core is represented by a region with 180 $\mathrm{cm}$ of diameter and a height of $197 \mathrm{~cm}$ according to [11]. In order to represent the region occupied by the fuel elements, a concentric system of cylindrical volumes was created, which represents the power regions, according to $[2,12]$. The representation of the fuel elements in the form of the realistic approach are shown in Figure 2, a).

According to [2], between the graphite and carbon blocks in the lower region of the reactor, part of the cooling gas flows without passing through the active zone. An estimative of $10 \%$ approximately of the nominal flow of the whole reactor. This volume of helium, leak toward the outlet duct without passing through the core of the reactor. Only are mixing with the hot helium in the hot plenum instant before the exit of the reactor. In this sense, the flow is represented by a group of 8 small channels that cross all the structural components, from the lower cavity of the reactor up to the hot plenum where it mixes with $90 \%$ of the hot helium that arrives from the reactor core. 
The Figure 2 a) represents realistic representation of solids materials and fuel elements using body-centered cubic array according to [16]; b) representation of a fluid path, the fuel elements like porous media and steel structural materials combined.

Figure 2: Geometric models of HTR-10 reactor.

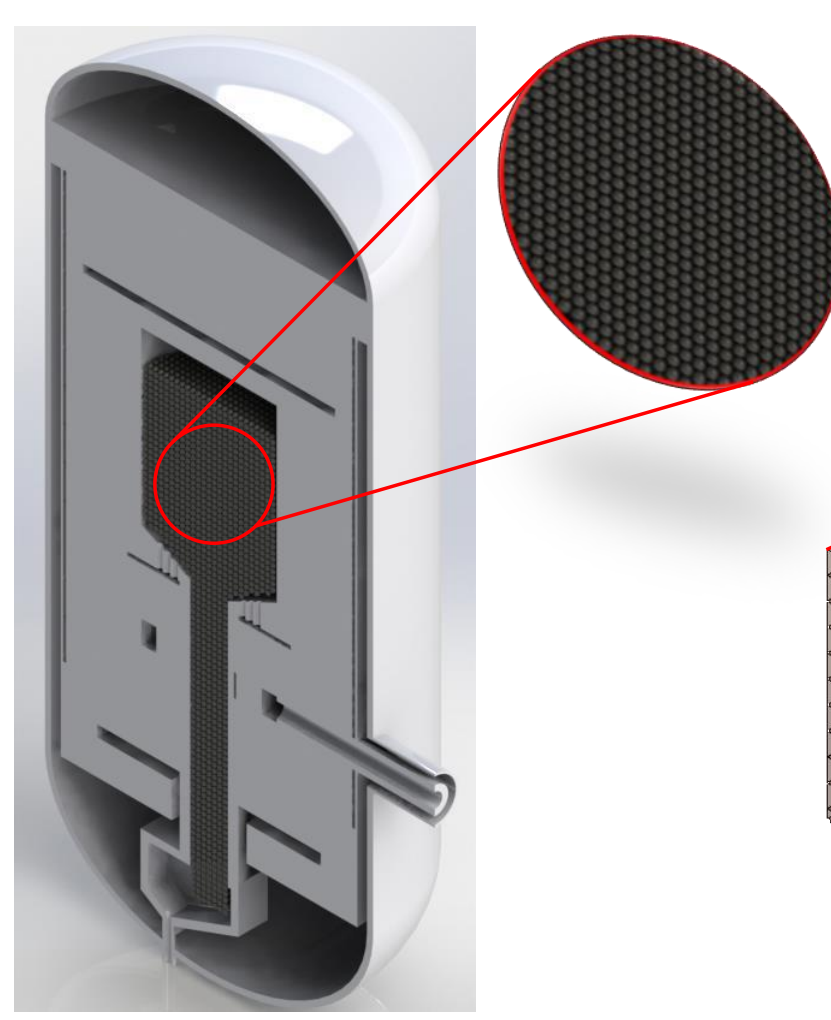

a)

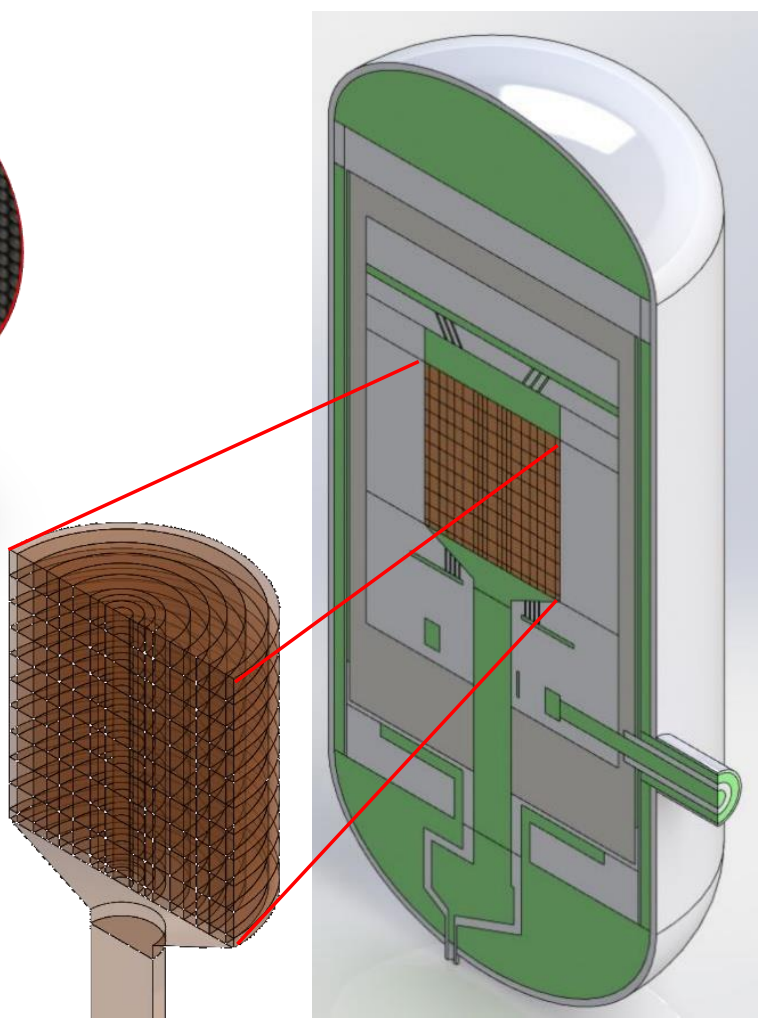

b)

According to [1, 17], was constructed the meshes of all the components of the geometric model of the reactor. This step was executed in the ANSYS Meshing module of ANSYS software's platform.

The distinctive feature of the mesh was the creation of inflation in all regions of contact between the fluid volumes and surfaces corresponding to the solid structures of the reactor. The creation of inflated meshes meets the requirements to model the thermal and hydrodynamic boundary layer throughout the reactor. The final meshes created also have the lowest index of orthogonality above 
0.2 which is a good quality. The final mesh was selected after several attempts during an analysis of independent mesh results. 


\subsection{The domain of numerical models: boundary conditions}

The subsequent step of modeling is the definition of the domains of each mathematical model used in conjunction with specific boundary conditions. This pre-processing step is carried out in the ANSYS CFX-Pre module.

For thermohydraulic analysis of the HTR-10 reactor, a correct domain configuration and mathematical models were necessary that simulate the physical phenomena. These configurations are determined by the description of the operating conditions according to $[1,3,18]$. The general description used is the proposal to the research teams involved in the test task for HTGRs proposed by the IAEA [3].

Figure 3: HTR-10 reactor computational configuration. a) Schematic representation of the domains; b) Plane of symmetry; c) Helium cooling flow.
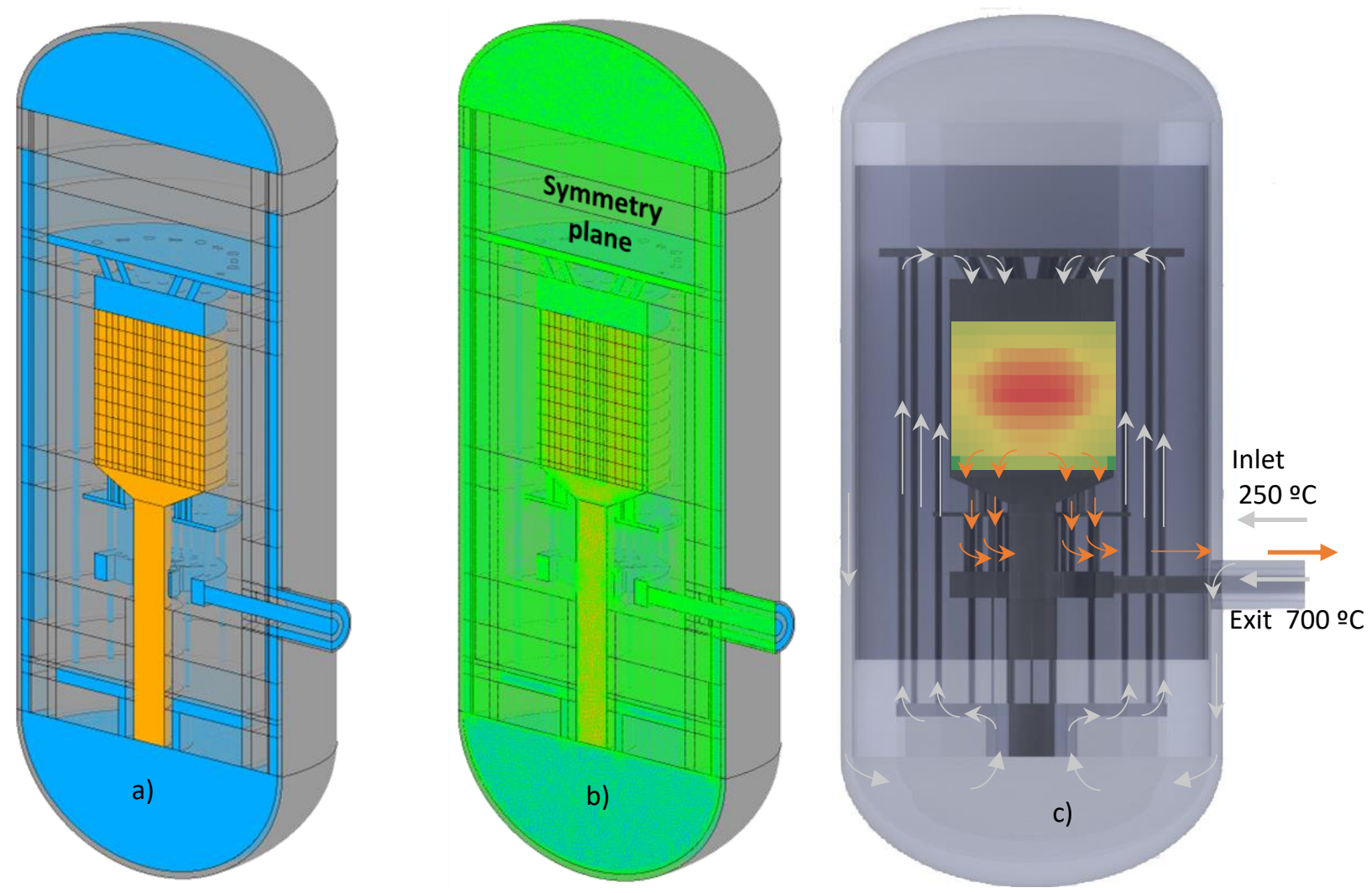

According to [17], computational domains were defined that interact with each other. A solid domain for every solid part, a porous domain (orange in Figure 3 a)) for the system of sections 
which represents the power core region of the reactor and the discharge channel, finally a fluid domain (blue in Figure 3) for the remaining volumes where the flow will be studied.

In order to decrease computational resources, symmetry configuration was considered by the axial plane as shown in Figure 3, b).

\subsection{Pebble bed porosity models}

The pebble bed core simulation of the HTR-10 reactor was carried out using a porous medium model proposed in ANSYS CFX. Some advantages and disadvantages of the porous medium used were discussed in [15].

The flow in ANSYS CFX porous media model [19] can be calculated using one of the following approximations at a time:

- A fluid domain together with a model for momentum loss. Where the effects of porosity are counted only for resistance to the fluid passage (pressure drop); all other terms in governing equations are not changed. As a result, such a formulation can be called superficial velocity formulation .

- A porous domain that involves one or more fluids and an optional solid. Porosity modifies all terms in the governing equations as well as the loss term. As a result, this formulation can be called the true velocity formulation or the full porous model. This method supports solid models (for example, for modeling thermal conductivity of the solid), and models for the interaction between the fluid and solid parts of the domain.

After considering the ideas discussed above, it was decided to use the ANSYS CFX full porous model. The full porous model has a porous solid heat transfer formulation which allows a finite temperature difference between the fluid phases and the solid phase. It is a non-thermal equilibrium model, therefore there are separate energy equations for each phase within the domain [19].

For the fluid phase and solid phase :

$$
\begin{aligned}
& \frac{\partial(\rho \varepsilon h)}{\partial t}+\nabla \cdot(\rho K \cdot U h)=\nabla \cdot\left(\lambda_{f} K \nabla T\right)+\varepsilon S_{E f}+Q_{f s} \\
& \frac{\partial\left(\rho_{s} \gamma_{s} h_{s}\right)}{\partial t}+\nabla \cdot\left(\rho_{s} K_{s} \cdot U_{s} h_{s}\right)=\nabla \cdot\left(\lambda_{f} K_{s} \nabla T_{s}\right)+\gamma_{s} S_{E s}+Q_{s f}
\end{aligned}
$$


where $\rho, U$ are the density and velocity;

solid fraction $\gamma_{s}=1-\varepsilon$, and the interfacial heat transfer to the fluid from the solid, $Q_{f s}$, is determined:

$$
Q_{f s}=-Q_{s f}=h A_{f s}\left(T_{s}-T_{f}\right)
$$

using an overall heat transfer coefficient model using:

$h$ : is the overall heat transfer coefficient between the fluid and the solid. And $A_{f s}$ is the interfacial area density between the fluids and the solid.

For the case of spherical pebbles

$$
A_{f s}=\gamma_{s} * \frac{6}{d}=(1-\varepsilon) * \frac{6}{d}
$$

Note that the porosity $(\varepsilon)$ has an important role in the whole heat transfer formulation.

In this way, the isotropic porosity model available in ANSYS CFX was used. Additionally, different functions were defined in CFX Expression Language (CEL) to introduce the different models of porosity.

In the IAEA benchmark [3], a constant bulk porosity of 0.39 was proposed for the entire region where fuel elements are found in the reactor. Neither the impact of the walls is taken into account. Additionally, the influence of the weight of the fuel elements on the local porosity is not considered. Due to the high density of the fuel elements and the high height of the core of the HTR-10 reactor, it is necessary to take into consideration the variation in the vertical direction of the local porosity. In [20] this influence is addressed. It is known that the thermomechanical behavior of the beds is highly influenced by the spatial variation of the porosity in the bed and in particular by the local porosity close to the walls [21-23]. Another feature that must be taken into consideration in the thermohydraulic analysis of the cores of the gas-cooled pebble bed reactors is that the coolant quickly changes its density by following the vertical direction inside the pebble beds. What qualifies an impact on the thermohydraulic efficiency of the heat transfer process. Nevertheless, in this work, the vertical variation of the porosity in the pebble beds has been neglected. 


\section{Radial porosity}

On the other hand, several experimental studies describe an oscillating tendency of the porosity, mainly close to the walls that contour the pebble bed. All point out that the porosity falls from a maximum value close to the unit, next to the wall of the bed till an average value (bulk porosity) further away from the wall. Gary E. Mueller in [24] proposes the equation (5) to estimate the bulk porosity with manifold good agreements.

$$
\varepsilon_{b}=0,365+\frac{0,220}{D / d}
$$

Several numerical $[20,22]$ and empirical [21, 24-26] studies agree that the oscillatory behavior is more accentuated up to a distance to the wall of 5 times the diameter of the particles, however, there are several empirical correlations that roughly describe this porosity trend. The empirical approximations are divided into two groups, which represent an oscillating behavior of the porosity in the bed and those that describe an exponential behavior of the vacuum fraction.

In $[23,25,26]$, among others, comparative studies of most empirical correlations are made. Highlighting the correlations of Hunt and Tien 1990 (equation 6) like the one that best represents the exponential tendency of the porosity fall near the bed wall to an average value in the center of the bed.

$$
\varepsilon_{(r)}=\varepsilon_{b} *\left[1+\frac{1-\varepsilon_{b}}{\varepsilon_{b}} * e^{\left(-6 * \frac{R-r}{d_{p}}\right)}\right] \quad \text { Hunt and Tien } 1990
$$

where $\varepsilon_{b}$ is the bulk porosity of the bed, ' 6 ' value is for the spherical shape of fuel elements, $R$ is the equivalent radios of the transversal section of the bed, $\mathrm{r}$ is the radial position and $d_{p}$ is the pebble's diameter.

In other approaches, Martin 1978 [25] (equation 7) and Klerk 2003 [23], are the best representant of the oscillatory behavior of the porosity in the pebble beds.

$$
\varepsilon_{(x)}=\left\{\begin{array}{c}
\varepsilon_{\text {min }}+\left(1-\varepsilon_{\text {min }}\right) x^{2},-1 \leq x \leq 0 \\
\varepsilon_{b}+\left(\varepsilon_{\text {min }}-\varepsilon_{b}\right) e^{-x / 4} \cos \left(\frac{\pi}{0.876} x\right), x \geq 0
\end{array}\right\} \text { Martin } 1978
$$


where $\varepsilon_{\min }$ is the minimum porosity $\varepsilon_{\min }=0,20-0,26$ and $x=2 \frac{R-r}{d_{p}}-1$.

In this work, the influence of the variation of the porosity near the walls of the pebble bed was analyzed.

Figure 4 shows a comparison result of tree different porosity model. The Uniform bulk porosity model which is proposed in the benchmark [3] like $\varepsilon_{b}=0.39$, corresponding to a 0.61 packing fraction. A oscillating semiempirical model proposed by Martin 1978 [23]. This model describe an oscillatory porosity property, mainly in a region that is influenced by the lateral walls of the cylinder that makes up the pebble bed of fuel elements. Additionally, Hunt and Tien 1990 model proposes an exponential effect of characteristic porosity in the pebble bed [23].

Figure 4: Comparison of porosity models

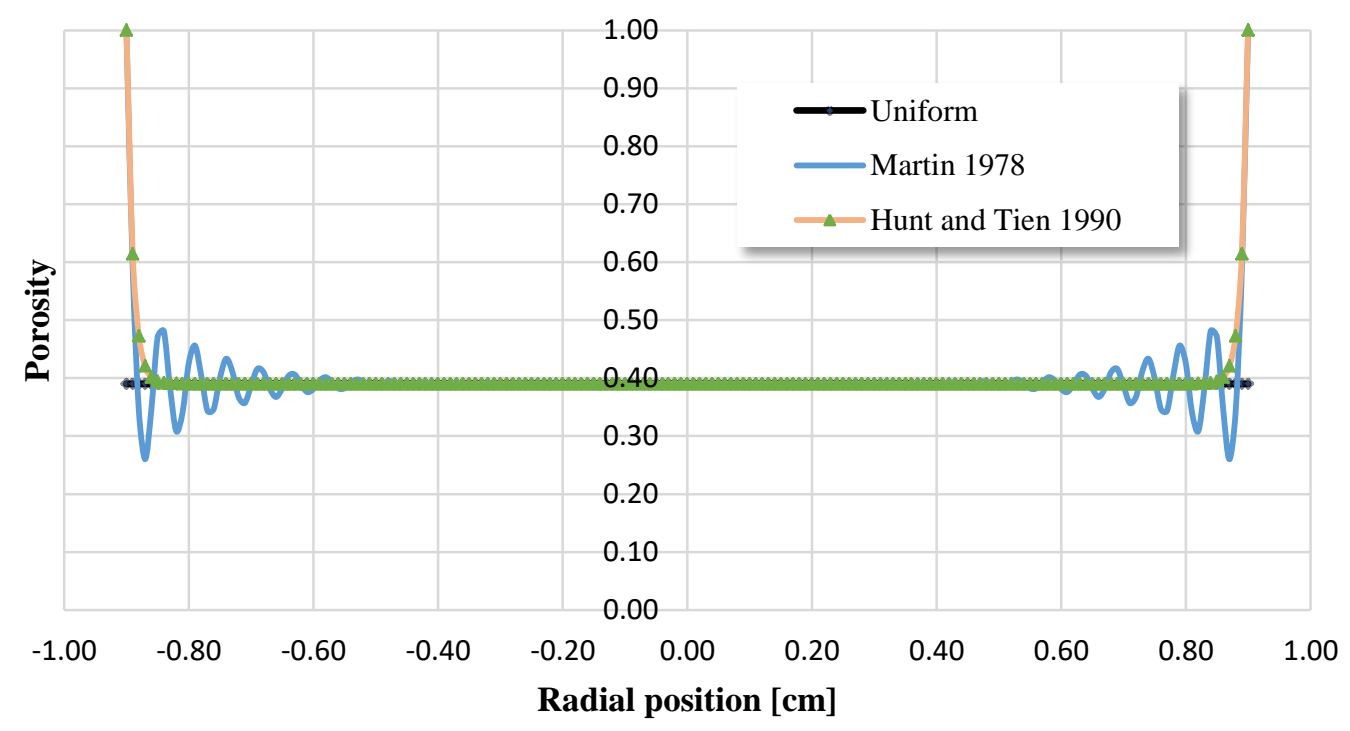




\section{RESULTS AND DISCUTIONS}

\subsection{Normal operation (steady-state)}

This section summarized the results obtained for some thermohydraulic parameters of the HTR10 reactor during the steady-state operating conditions proposed by the IAEA benchmark [3] at fullpower. In addition, is shown the comparison of the results of the simulations corresponding to the three porosity models discussed in section 2.4 .

Figure 5 a), shows a constant porosity approach with $\varepsilon_{b}=0.39$; in the middle of Figure $5, \mathrm{~b}$ ) is shown with colorimetric scale an oscillatory porosity using the Martin 1978 approach; and the right Figure 5, c) is shown an exponential porosity proposed by Hunt and Tien 1990 approximation. The last, has a homogeneous porosity value develop at the center of the core region and grow with ex-

Figure 5: Porosity representation in the pebble bed. a) Uniform bulk porosity model; $b$ ) Martin 1978 oscillatory porosity model; c) Hunt and Tien 1990 exponential porosity mod-

el.

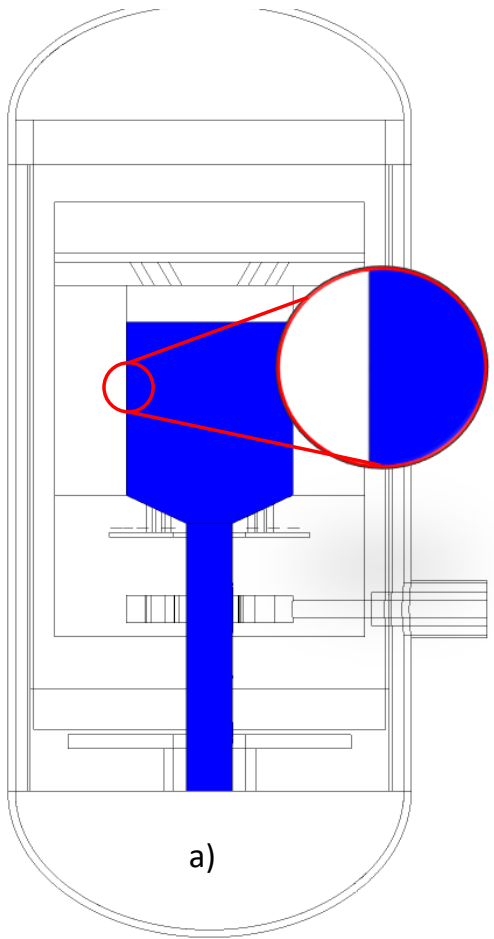

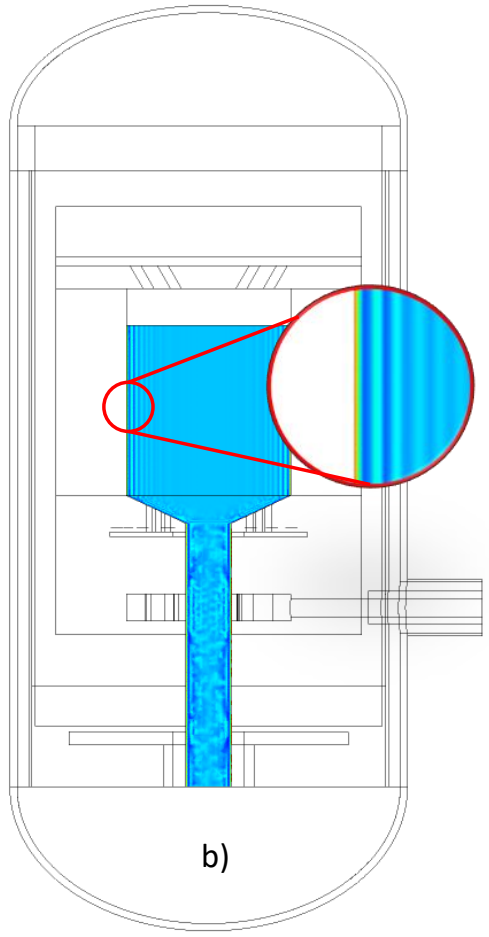

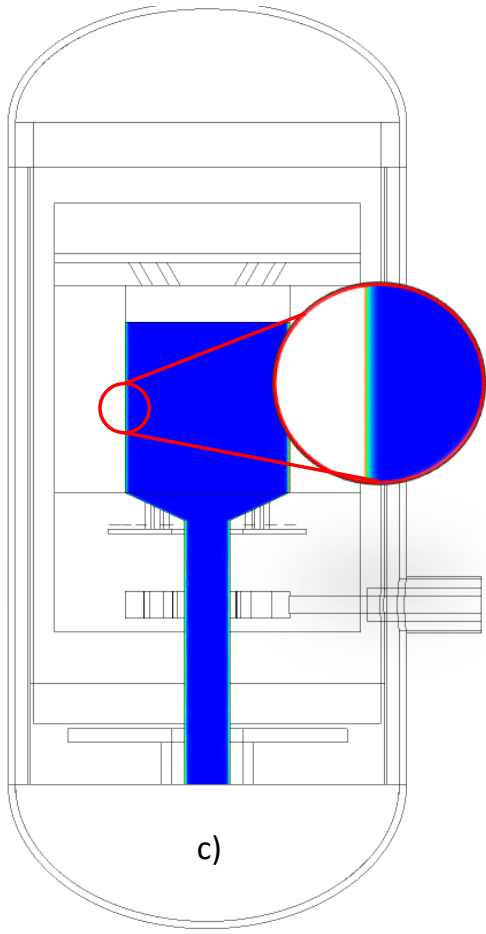

ponential form till near de unit porosity value near the wall region. 
After concluding the corresponding simulations, the profiles of the main thermohydraulic parameters were obtained. The temperature profile is shown in Figure 6. It is possible to identify that helium temperature with bulk homogeneous porosity model in the reactor core is lower than helium temperature with variable porosity models. Also, the temperature profile of structural components like side reflector and bottom reflector is higher with bulk homogeneous porosity model than using variable porosity models. In Figure 6 b) and Figure $6 \mathrm{c}$ ), are identified that the temperature behavior has a very similar tendency using the variable porosity models. The temperatures obtained with Hunt and Tien 1990 model is slightly higher than the temperature obtained using the Martin model.

Figure 6: Helium and structural components temperature profile in steady-state 10MW of thermal power. a) Uniform bulk porosity model, b) Martin 1978 oscillatory porosity model, c) Hunt and Tien 1990 exponential porosity model.
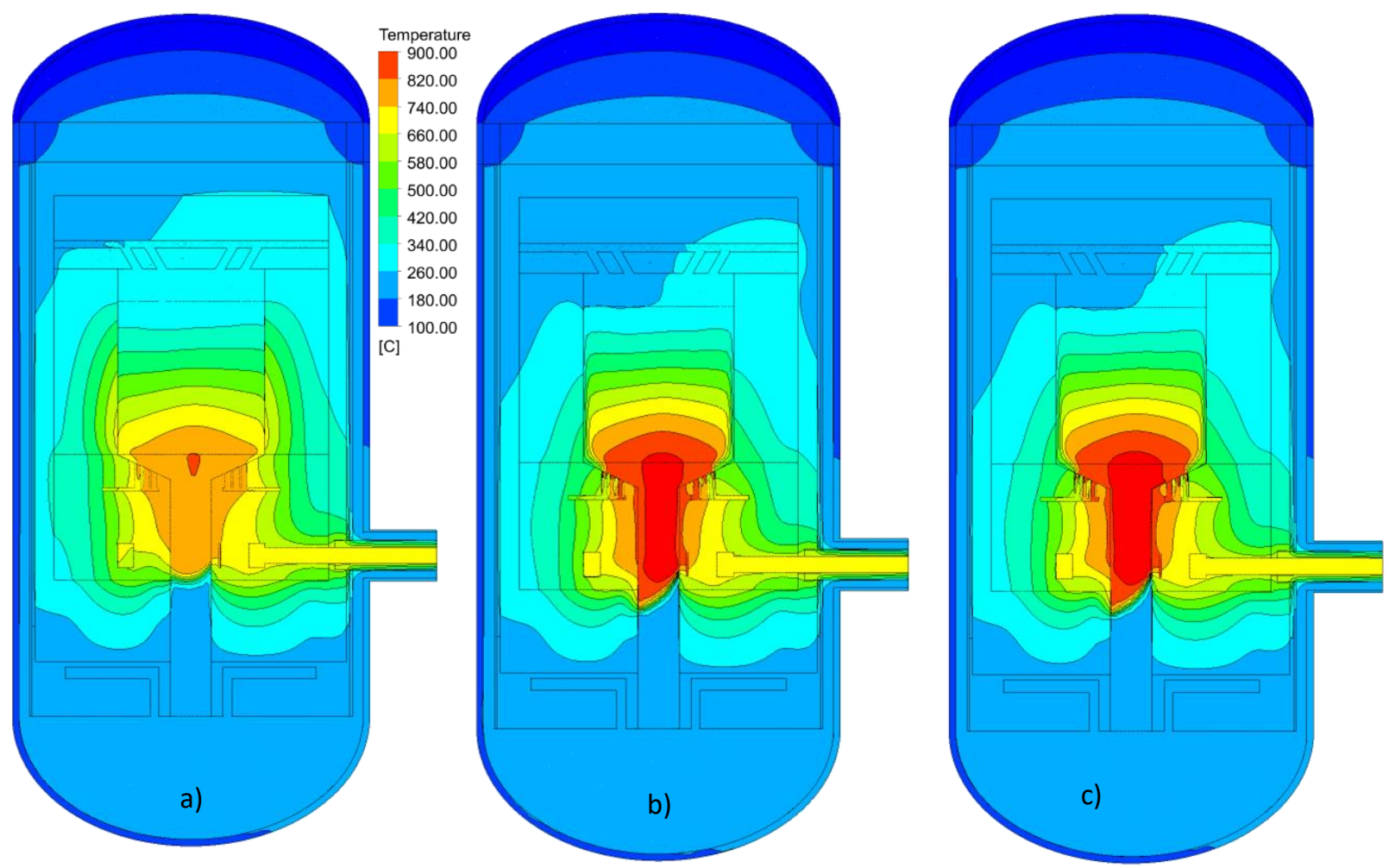

The charts in Figure 8 and Figure 9 show the maximum temperature reached in the middle of the reactor core, exactly at the black line showed in Figure 7. That temperature varies depending on the model used. The maximum temperature reached using the three porosity models was: $931.6^{\circ} \mathrm{C}$ 
(using the Hunt and Tien 1990 model), $920.1^{\circ} \mathrm{C}$ (using the Martin 1978 model) and $821.5^{\circ} \mathrm{C}$ (using the bulk homogeneous porosity model) in the helium cooling flow respectively. Little more than 100 degrees of difference between the bulk homogeneous porosity model and the variable porosity models. Analyzing the maximum temperature reached at the fuel elements using the three porosity models: $1007.7^{\circ} \mathrm{C}$ (Hunt and Tien 1990 model), $997.1^{\circ} \mathrm{C}$ (Martin 1978 model) and $943.3^{\circ} \mathrm{C}$ (bulk homogeneous porosity model) in the helium cooling flow respectively. In general, is observed 100 degrees of difference between the bulk homogeneous porosity model and the variable porosity models. The maximum temperatures reached in the fuel elements are estimated as lower than the limit safety temperature limitation of $1230^{\circ} \mathrm{C}$.

Figure 7: References lines position for temperatures calculation

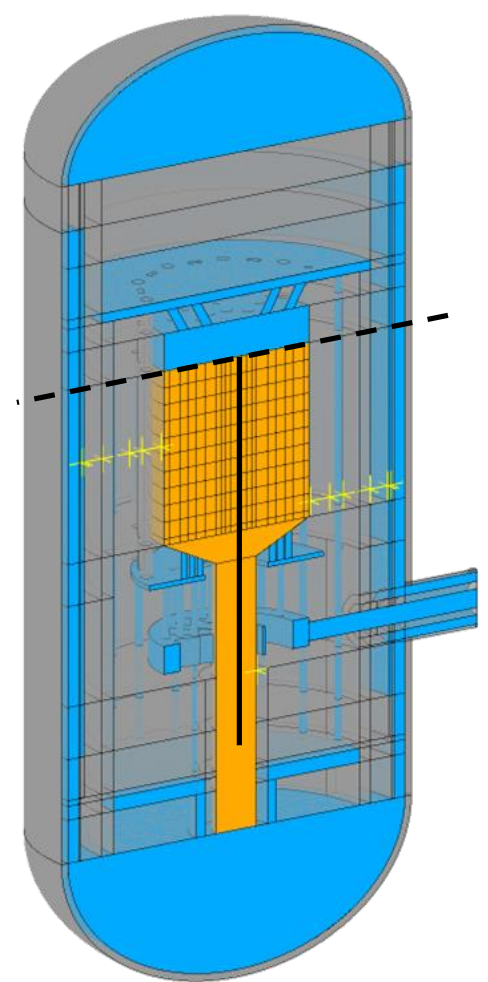

The dashed line indicates the position as a reference $0[\mathrm{~m}]$ for axial axis which is the start of coolant penetration in the pebble bed.

Figure 8: Temperature profile at the middle axial position

Figure 9: Fuel elements temperature pro-

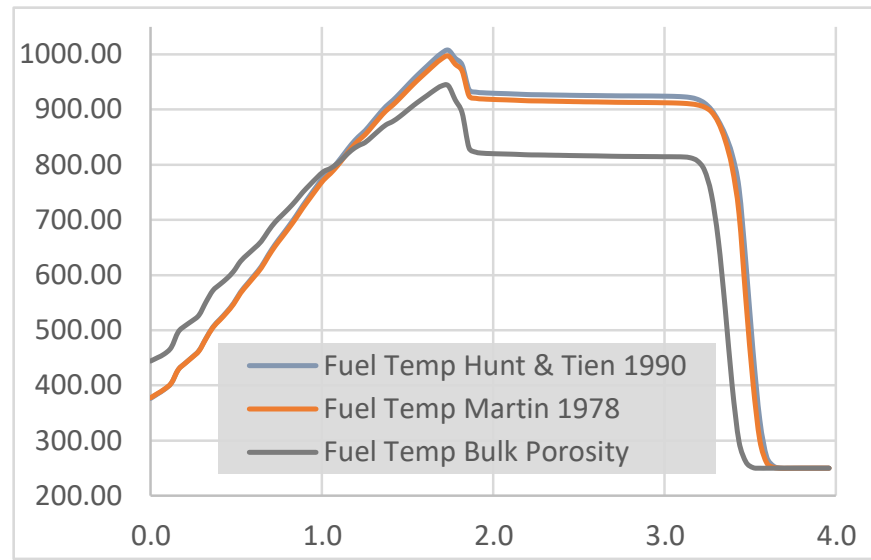

file at the middle axial position.

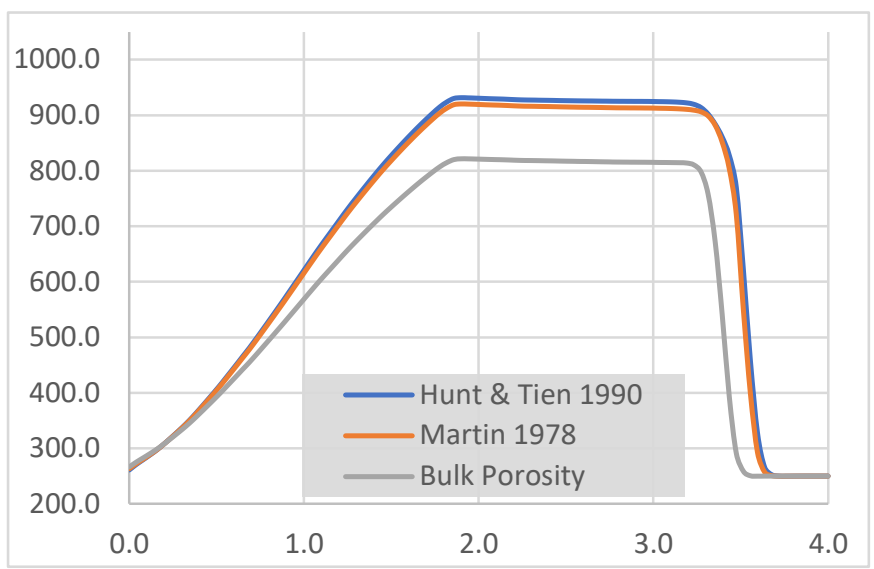


The marked difference of temperature profile is possible to explain from the following effect: with increasing porosity in the region near the wall due to the crystallization effect, it increases the passage of coolant in the proximity of the walls and an increase in the cooling of the region. This causes a decrease in the heat transferred to the reflector and a decrease in the temperature in the reflector. During normal operation where the forced circulation system is which control the heat transfer at the pebble bed core, the porosity variable impacts are small. The passive safety design of HTR-10 is not to be affected

In contrast, since the natural circulation phenomenon dominates the heat transfer in the reactor, it will be less favored the heat transfer between the region with high presence of $\mathrm{He}$ (more porosity) and the structural materials of the reactor. This could cause an increase in the temperature of the coolant in the fuel elements. Hence the importance of studying the behavior of the reactor under accident conditions.

\subsection{Anticipated Transients Without Scram (ATWS)}

Several safety demonstrations experiments have been carried out at the HTR-10 reactor since 2003. Some experimental results were published [3], [27]-[30]. In this work, the data corresponding to the Helium circulator trip without scram at $3 \mathrm{MW}$ was used. Firstly, the reactor was carried out to $30 \%$ of the full power (3MW) as from an inlet helium temperature of $215^{\circ} \mathrm{C}$ and an outlet temperature of $650^{\circ} \mathrm{C}$ until stability was achieved. At this point, the test began with the shutdown of the helium circulator which is who of maintaining the forced cooling in the primary circuit. Until the total stop of the movement of the cooling gas, forced circulation is the main process of extracting heat from the reactor. Once stops or stagnation of the cooling gas has been reached, the heat exchange process involved in the Reactor Cooling Cavity System (RCCS) becomes the priority in the cooling of reactor fuel elements. After 12 seconds of the test starts, the protection system is initiated by the signal of power increasing rate is high . Automatically, the flapper valve in the primary circuit was closed and the secondary circuit was isolated. Control bars are not inserted. After the helium circulator was switched off, the reactor power was decreased due to negative reactivity feedback caused by the rising of temperature in the core because of the decreasing heat removal capability of the primary circuit. This physical feature is a passive safety capability of this nuclear reactor. 
In this case, was used the variable porosity model according to the Hunt and Tien model to simulate this transient state. Firstly was modeled the stationary start point corresponding at $3 \mathrm{MW}$ of thermal power according to [29]. The core power distribution at this point was used according to [3].

To simulate the decrease of nuclear power in the reactor core, the following approximation was used: first, the response curve of the overall power of the reactor was obtained from [30]. This curve was published and recommended by IAEA from the post-experimental test. Then the power density of each core region that had been calculated for the initial steady-state by this power response curve was multiplied. In this way, a thermohydraulic neutron coupling was not used for the simulation. Similarly, was done to simulate the helium circulator mass flow response, Figure 10.

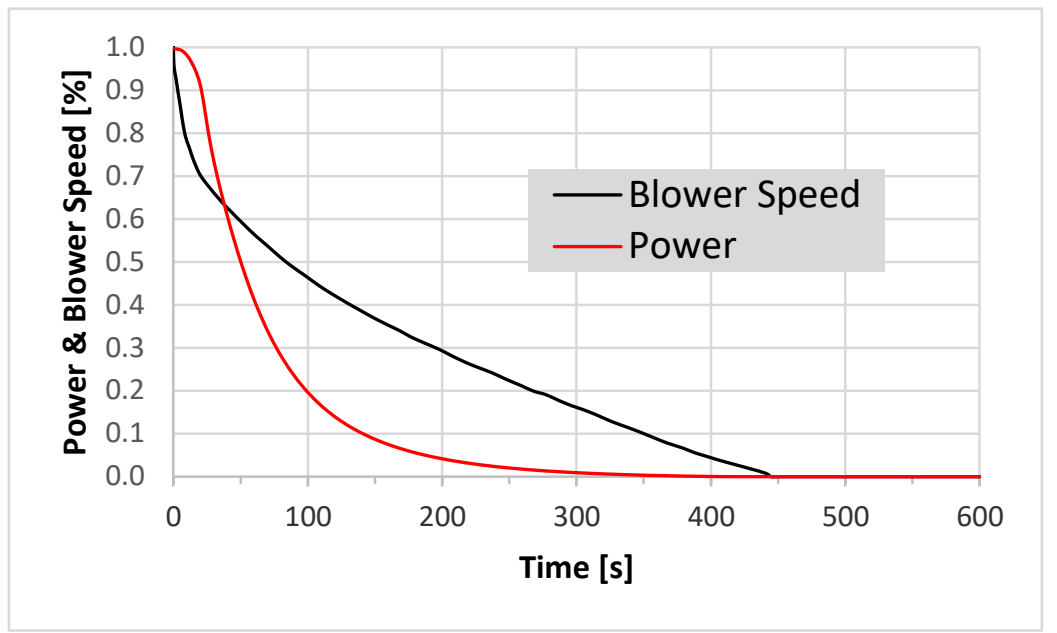

Figure 10: Blower speed and Fission Power.

The temperature distribution in the axial middle plane, during the first $10 \mathrm{~min}$ of the transient test corresponding to the blower's circulator trip without scram, is shown in Figure 11. The maximum temperature in the coolant starts to up from $720^{\circ} \mathrm{C}$ slightly to $738^{\circ} \mathrm{C}$ and then goes down slowly. Similar behavior is presented by the fuel's elements at this point in Figure 12. 


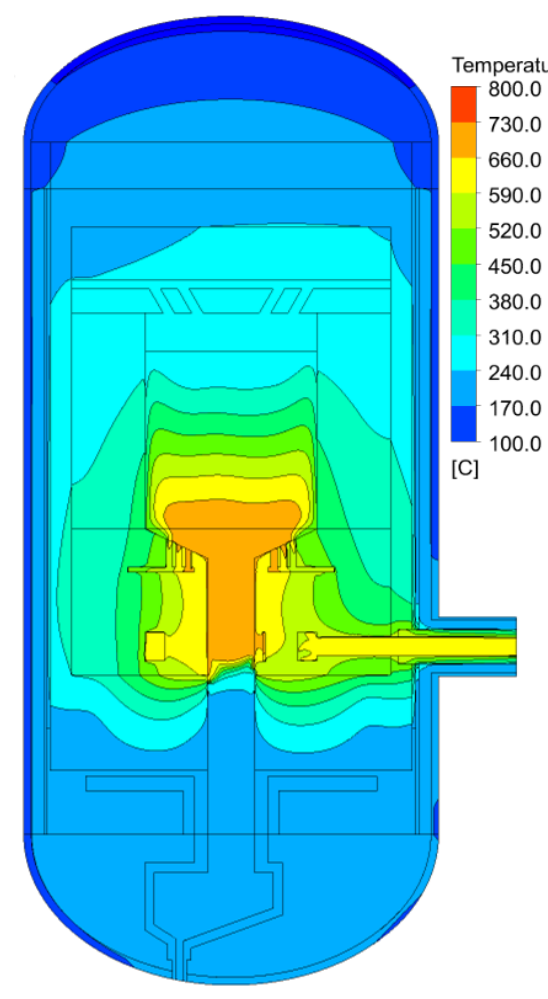

Os

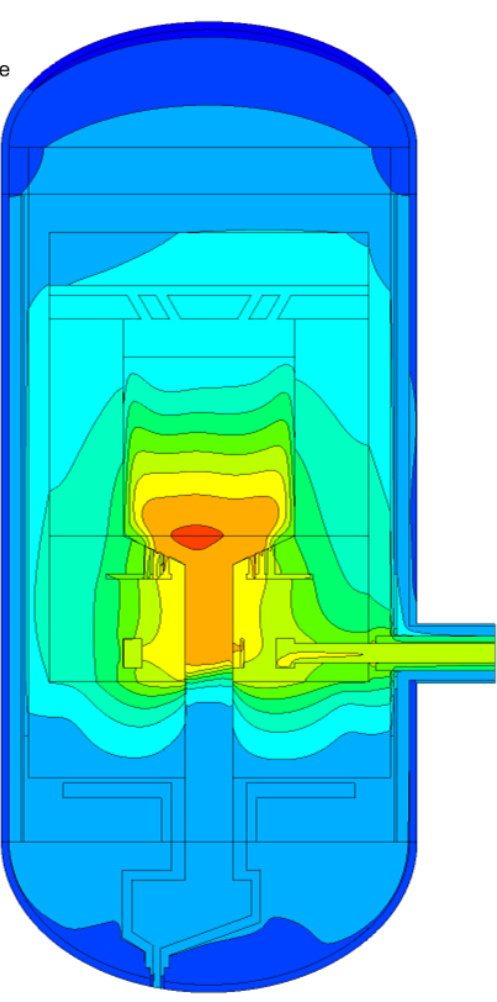

300s

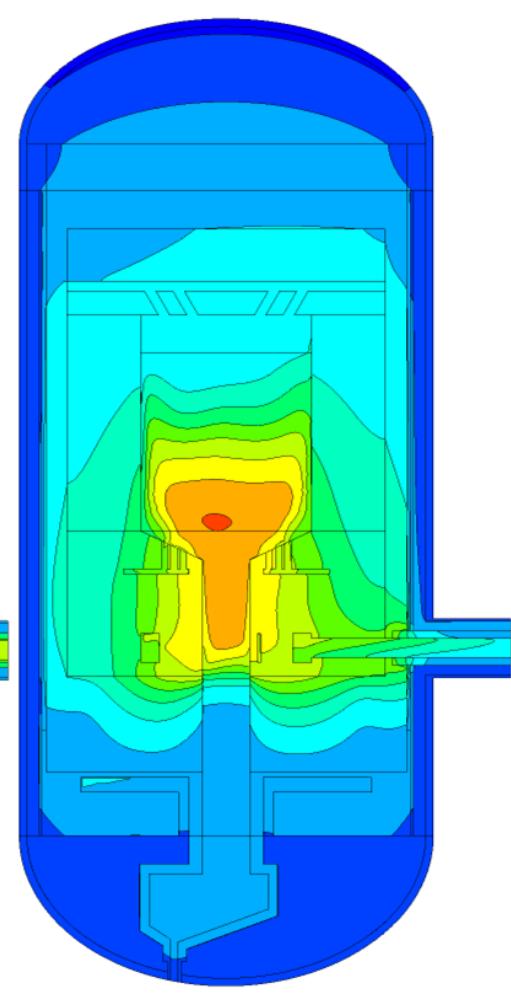

$600 \mathrm{~s}$

Figure 11: Helium and structural components temperature profile at Anticipated Transients Without Scram (ATWS).

An interesting key feature, obtained from the transient simulation, is that the maximum temperatures were obtained slightly displaced from the central axis of the reactor, as shown in Figure 11. A displacement in the evolution of the temperature profiles making it less symmetric. Figure 12, also shows how the entire reactor is cooled by the walls of the RPV due to the external performance of the Reactor Cooling Cavity System (RCCS) due to as from 450s are not more forced circulating rate. 
Figure 12: Maximum Fuel elements and Helium coolant temperatures.

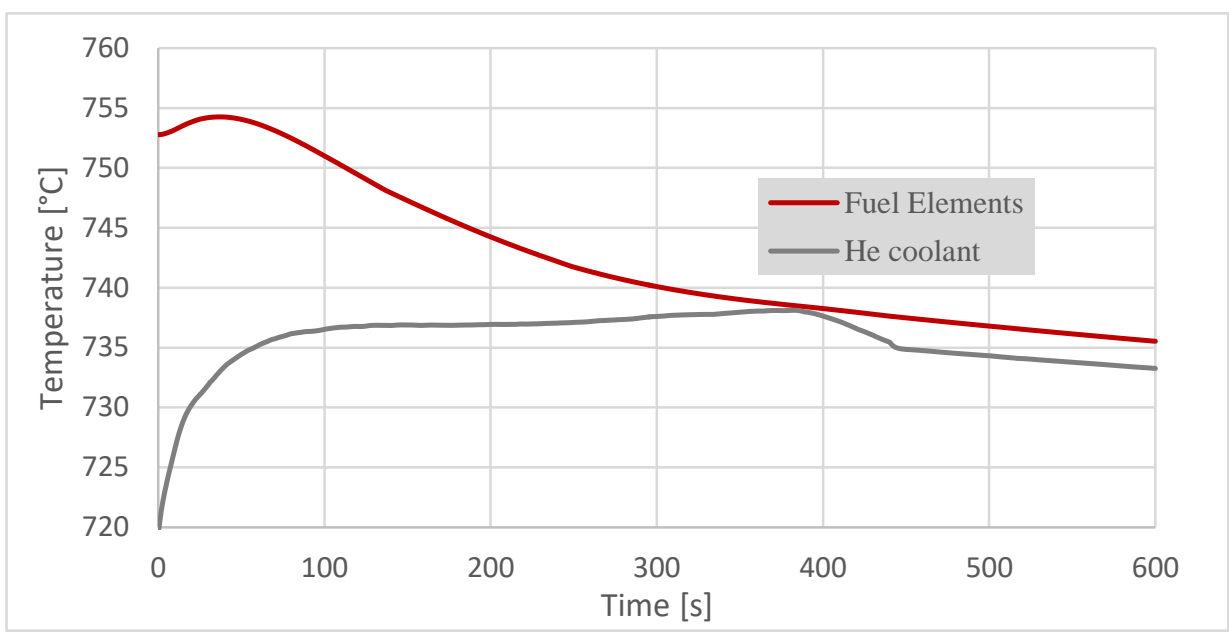

\section{CONCLUSIONS}

The three-dimensional CFD thermohydraulic simulation of the steady-state of the HTR-10 reactor at $10 \mathrm{MW}$ and $3 \mathrm{MW}$ of thermal power was carried out. The 3D full-scale representation of reflector zone and fluid path, flow inner and outer reflector blocks, and cold helium cavity was carried out. The porous medium model was used to simulate the core fuel zone of the reactor. The impact of porosity of pebble beds in the thermohydraulic performance under normal operation was investigated. Also, the thermohydraulic calculation under accident condition using an exponential porosity model in the pebble bed reactor core was achieve.

Some important conclusions could be drawn from the present simulations and would be presented as follows:

- The three different porosity models were used to study the impact in the temperature profile at normal power operation.

- The coolant temperature profile modeled using the bulk homogeneous porosity model in the reactor core is lower than coolant temperature profiles using the variable porosity models.

- With increasing porosity in the region near the wall due to the crystallization effect, it increases the passages of coolant in the proximity of the walls and an increase of the cooling of the 
region. This causes a decrease in the heat transferred to the reflector and a decrease in the temperature in the reflector.

\section{ACKNOWLEDGMENTS}

This work has been carried out in the framework of technological cooperation supported by the CNPq (Conselho Nacional de Desenvolvimento Científico e Tecnológico), the UFPE (Universidade Federal de Pernambuco) and the NBCGIB (Núcleo de Biologia Computacional e Gestão de Informações Biotecnológicas), of the Universidade Estadual de Santa Cruz (UESC).

\section{REFERENCES}

[1] IEA, Global Energy and CO2 Status Report, OECD-IEA, 2018.

[2] NERAC, A Technology Roadmap for Generation IV Nuclear Energy Systems, NERAC, 2002.

[3] IAEA, Evaluation of High Temperature Gas Cooled Reactor Performance: Benchmark Analysis Related to the PBMR-400, PBMM, GT-MHR, HTR-10 and the ASTRA Critical Facility, IAEA, Vienna, 2013.

[4] J. Xingqing and Y. Yongwei, Physical Designs and Calculations for the First Full Power Operation of the 10Mw High Temperature Gas- Cooled Reactor — Test Module ( Htr-10 ) High Temp., pp. 1-7, 2004.

[5] IAEA, Evaluation of high temperature gas cooled reactor performance: Benchmark analysis related to initial testing of the HTTR and HTR-10, IAEA, Vienna, 2003.

[6] IAEA, Heat Transport and Afterheat Removal for Gas Cooled Reactors Under Accident Conditions, Vienna, 2000.

[7] IAEA, Heat Transport and Afterheat Removal for Gas Cooled Reactors Under Accident Conditions, Vienna, 2001.

[8] A. Gámez R. et al., FULL SCALE CFD THERMOHYDRAULIC CALCULATION OF HIGH TEMPERATURE PEBBLE BED NUCLEAR REACTOR, in International Nuclear Atlantic Conference - INAC 2017, 2017.

[9] Z. Gao and L. Shi, Thermal hydraulic calculation of the HTR-10 for the initial and equilibrium core, Nucl. Eng. Des., vol. 218, no. 1-3, pp. 51-64, 2002.

[10] Z. Zhang, J. Liu, S. He, Z. Zhang, and S. Yu, Structural design of ceramic internals of HTR10, Nucl. Eng. Des., vol. 218, no. 1-3, pp. 123-136, 2002. 
[11] Z. Wu, D. Lin, and D. Zhong, The design features of the HTR-10, Nucl. Eng. Des., vol. 218, no. 1-3, pp. 25-32, 2002.

[12] G. Zuying and S. Lei, Thermal hydraulic transient analysis of the HTR-10, Nucl. Eng. Des., vol. 218, no. 1-3, pp. 65-80, 2002.

[13] F. Chen, Y. Dong, Y. Zheng, L. Shi, and Z. Zhang, Benchmark Calculation for the SteadyState Temperature Distribution of the HTR-10 under Full- Power Operation, J. Nucl. Sci. Technol., vol. 46, no. December 2012, pp. 572-580, 2009.

[14] H. Zhao, Y. Dong, Y. Zheng, T. Ma, and X. Chen, Numerical simulation on heat transfer process in the reactor cavity of modular high temperature gas-cooled reactor, Appl. Therm. Eng., vol. 125, pp. 1015-1024, 2017.

[15] Z. Li, Huaixuan, Zhang, Yajun, Li, HTR-10 primary cavity cooling system and its features, Tsinghua Univ, Beijing, China, vol. 38, no. 5, pp. 99-101, 1998.

[16] L. Capone, Y. A. Hassan, and R. Vaghetto, Reactor cavity cooling system (Rccs) experimental characterization, Nucl. Eng. Des., vol. 241, no. 12, pp. 4775-4782, 2011.

[17] W. K. Terry et al., EVALUATION OF THE INITIAL CRITICAL CONFIGURATION OF THE HTR-10 PEBBLE-BED REACTOR, 2007.

[18] L. García, Diseño conceptual de un sistema controlado por un acelerador para transmutación de residuos nucleares y aplicaciones energéticas, Universidad Politécnica de Valencia, Valencia, 2012.

[19] A. S. Silva, L. Y. Rojas, D. S. Dominguez, C. R. García, A. Gámez, and C. A. Brayner, Realistic CFD simulation of HTR-10 reactor using a face centred cubic column, Int. J. Nucl. Energy Sci. Technol., vol. 10, no. 3, 2016.

[20] L. Y. Rojas, L. García, C. R. García, F. A. Escrivá, and C. A. Brayner, Thermal-hydraulic studies of a transmutation advanced device for sustainable energy applications, Int. J. Nucl. Energy Sci. Technol., vol. 9, no. 4, 2015.

[21] C. Y. Wu, Y. M. Ferng, C. C. Chieng, and C. C. Liu, Investigating the advantages and disadvantages of realistic approach and porous approach for closely packed pebbles in CFD simulation, Nucl. Eng. Des., vol. 240, no. 5, pp. 1151-1159, 2010.

[22] L. Rojas Mazaira, D. Sanchez Dominguez, C. García, A. Gámez Rodríguez, and C. Brayner, Realistic CFD simulation of compressible flow inside the core of the Pebble Bed Reactor HTR-10., in 1st Pan-American Congress on Computational Mechanics - PANACM 2015, 2015, pp. 840-848.

[23] A. Gámez et al., CFD thermohydraulic calculation for the steady-state of the real scale HTR10, in International Nuclear Atlantic Conference - INAC 2015, 2015.

[24] A. Gámez, L. Rojas, D. S. Domínguez, J. Rosales, and Y. Landy, CFD thermohydraulic calculation for the steady-state of the real scale HTR-10, in International Nuclear Atlantic Conference - INAC 2015, 2015.

[25] I. ANSYS, ANSYS CFX Solver Theory Guide, 15.0. Canonsburg, PA: ANSYS, Inc., 2013. 
[26] X. Yang, N. Gui, J. Tu, and S. Jiang, 3D DEM simulation and analysis of void fraction distribution in a pebble bed high temperature reactor, Nucl. Eng. Des., vol. 270, pp. 404411, 2014.

[27] M. Suzuki, T. Shinmura, K. Iimura, and M. Hirota, Study of the wall effect on particle packing structure using X-ray micro computed tomography, Adv. Powder Technol., vol. 19, no. 2, pp. 183-195, 2008.

[28] J. Theuerkauf, P. Witt, and D. Schwesig, Analysis of particle porosity distribution in fixed beds using the discrete element method, Powder Technol., vol. 165, no. 2, pp. 92-99, 2006.

[29] W. Van Antwerpen, C. G. Toit, and P. G. Rousseau, A review of correlations to model the packing structure and effective thermal conductivity in packed beds of mono-sized spherical particles, Nucl. Eng. Des., vol. 240, no. 7, pp. 1803-1818, 2010.

[30] G. E. Mueller, Radial void fraction distributions in randomly packed fixed beds of uniformly sized spheres in cylindrical containers, Powder Technol., vol. 72, pp. 269-275, 1992. 